\title{
Forskolin up-regulates aromatase (CYP19) activity and gene transcripts in the human adrenocortical carcinoma cell line H295R
}

\author{
M Watanabe and S Nakajin \\ Department of Biochemistry, Hoshi University School of Pharmacy and Pharmaceutical Sciences, 2-4-41 Ebara, Shinagawa, Tokyo 142-8501, Japan \\ (Requests for offprints should be addressed to M Watanabe; Email: masatada@hoshi.ac.jp)
}

\begin{abstract}
A number of conditions related to sex-reversal in boys and men and precocious puberty in girls are caused by estrogen-secreting adrenal tumors. In these tumors, cytochrome P450 aromatase (aromatase) that is encoded in the CYP19 gene is expressed at high levels. To investigate the molecular mechanism of aromatase expression in these adrenal tumors, we characterized the activity, gene transcript and genomic promoter region of aromatase in the human adrenocortical carcinoma cell line H295R. Aromatase activity and the transcript of the CYP19 gene were highly up-regulated by forskolin, but not by dexa-
\end{abstract}

methasone. The results from exon I-specific reverse transcriptase (RT)-PCR and the transfection of reporter constructs suggested that promoter I.3 and promoter II were activated in H295R. Deletion and mutation analysis suggested that cAMP response element-like sequence (CLS) and steroidogenic factor-1 (SF-1) motif, were critical for the activation of promoter II. The results of this work should provide the basis for the molecular analysis of aromatase expression in adrenocortical cells.

Journal of Endocrinology (2004) 180, 125-133

\section{Introduction}

Estrogen-secreting adrenal tumors may cause precocious puberty in girls and sex-reversal in boys and men (Young et al. 1996, Watanabe et al. 2000, Phornphutkul et al. 2001). Abnormally high serum concentrations of estrogen cause gynecomastia in boys and men and very early menarche in girls. In these adrenal tumors, cytochrome P450 aromatase (aromatase) that is encoded in the CYP19 gene is highly expressed, whereas normal adrenal tissues have no detectable aromatase activity.

Aromatase is the final and rate-limiting enzyme of estrogen biosynthesis. Multiple signaling pathways regulate expression of aromatase activity and CYP19 gene transcripts. In ovary, aromatase activity can be stimulated by an increase in the intracellular cAMP concentration in response to tropic stimulation by follicle-stimulating hormone (Simpson et al. 1997). In human osteoblasts, aromatase activity can be stimulated by glucocorticoids (Shozu \& Simpson 1998). In human adipose stromal cells aromatase activity can be stimulated by both cAMP and glucocorticoids (Zhao et al. 1995, Simpson et al. 1997). In response to the multiple signals, multiple promoters are activated and multiple species of exon I are selected as a consequence of alternative splicing (Fig. 1) (Simpson et al. 1997, Sasano \& Harada 1998, Sebastian \& Bulun 2001); for example, exon I.3 and exon PII are selected in the ovary. Proximal promoters of these species of exon I

(promoter I.3 and promoter II), which have a cAMP response element (CRE)-like sequence (CLS) or CREaro, are activated in a cAMP-dependent manner. In human osteoblasts, exon I.4 is selected as the $5^{\prime}$-untranslated region of the CYP19 gene transcript. Its proximal promoter region (promoter I.4), which has the glucocorticoid response element (GRE), is activated by glucocorticoids. In adipose stromal cells, exon I.3, exon PII and exon I.4 are selected. Central nervous system-specific CYP19 exon I (exon 1f) was identified in mice and humans (Honda et al. 1996, Sasano et al. 1998). Studies on estrogen-secreting adrenal tumors have revealed that exon I.3 and/or exon PII are selected in the CYP19 gene transcript (Young et al. 1996, Watanabe et al. 2000).

Precise characterization of the response to hormones and chemicals, as well as the molecular mechanisms involved, is needed for the development of treatment for estrogen-secreting adrenal tumors. For this characterization work, an adrenal tumor cell line that has the same profile in vivo as estrogen-secreting adrenal tumors would be a useful tool.

In the present study, we characterized the expression of aromatase activity and CYP19 gene transcript in the human adrenocortical carcinoma cell line H295R. H295R is a well-known steroidogenic cell line that synthesizes adrenal androgens and cortisol (Gell et al. 1998, Ohno et al. 2002). Expression of aromatase activity has been reported in some studies (Sanderson et al. 2000, 2001a,b, 2002), but 


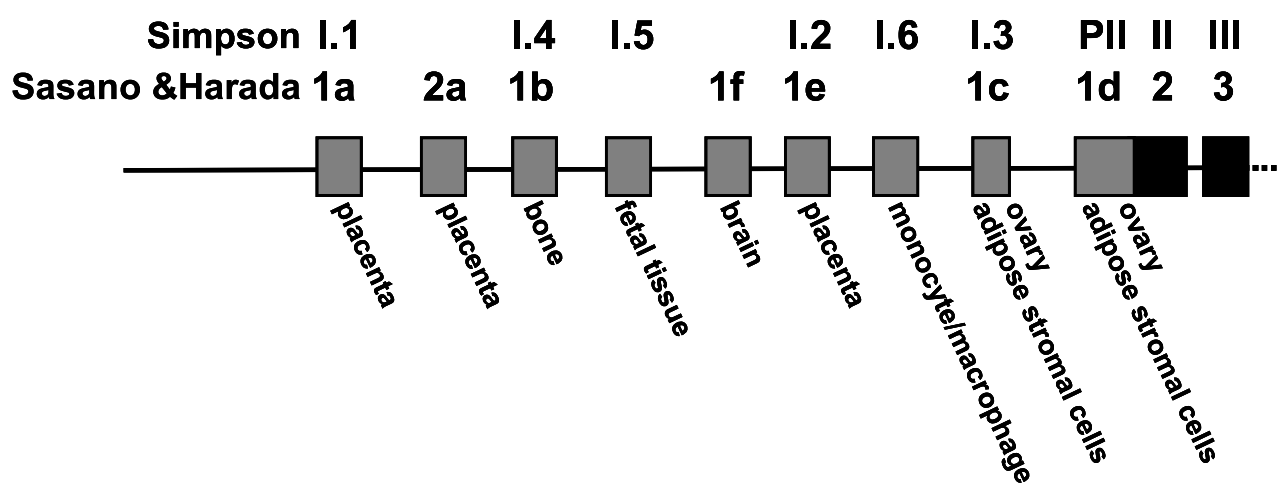

Figure 1 Partial structure of CYP19 gene. Nomenclature of multiple exon I by Simpson et al. (1997) and Sasano and Harada (1998) and well-known tissues of exons I selection are indicated. Location of exon I is based on the analysis of the human genome sequence by Sebastian and Bulun (2001).

its precise molecular mechanism is still not clear. We also characterized the profile of the activity of the CYP19 promoter region. The results of this work should provide the basis for the molecular analysis of aromatase expression in malignant adrenocortical cells.

\section{Materials and Methods}

\section{Materials}

Forskolin was purchased from Wako Pure Chemical Industries (Osaka, Japan) and dexamethasone was obtained from Sigma. Both compounds were dissolved in ethanol, and the final concentration of ethanol in the medium was $0 \cdot 1 \% \quad(\mathrm{v} / \mathrm{v})$. Dulbecco's modified Eagle's medium (DMEM)/F-12 medium and the mixture of penicillin $(5000 \mathrm{U} / \mathrm{ml})$ and streptomycin $(5000 \mu \mathrm{g} / \mathrm{ml})$ were obtained from Invitrogen. DMEM and BSA F-V (BSA) were obtained from Sigma and Nacalai Tesque (Kyoto, Japan) respectively. Other reagents and materials used included: ITS plus (insulin, transferrin, selenium; BD Biosciences, Bedford, MA, USA); Ultroser G (Biosepra S.A., CergySaint-Christophe, France); fetal calf serum (FCS; Sanko Junyaku, Tokyo, Japan); ISOGEN (Nippongene, Toyama, Japan); oligonucleotide primers (Sigma Genosys Japan, Hokkaido, Japan); Fugene 6 transfection reagent (Roche); avian myeloblastosis virus (AMV) reverse transcriptase, Taq DNA polymerase, pGL3-Basic, phRL-TK, Dual-Luciferase reporter assay system, and restriction enzymes (Promega); human placenta ribonuclease inhibitor (Takara Shuzo, Shiga, Japan); $\left[1 \beta_{-}{ }^{3} \mathrm{H}\right]$ androstenedione, ACS II aqueous counting scintillant and Oligo dT primer $\left(\operatorname{pd}(\mathrm{T})_{12-18}\right)$ (Amersham); BCA protein assay kit (Pierce, Rockford, IL, USA); Quikchange site-directed mutagenesis kit and Pfu Turbo DNA polymerase (Stratagene, La Jolla, CA, USA); Sirius luminometer (Berthold Detection Systems, Pforzheim, Germany).

\section{Cells}

The H295R human adrenocortical carcinoma cell line was a kind gift from Prof. J I Mason (University of Edinburgh, Edinburgh, UK). H295R cells were maintained in DMEM/F-12 medium supplemented with $2 \%(\mathrm{v} / \mathrm{v})$ Ultroser $\mathrm{G}, 1 \%(\mathrm{v} / \mathrm{v})$ ITS plus, penicillin $(25 \mathrm{U} / \mathrm{ml})$ and streptomycin $(25 \mu \mathrm{g} / \mathrm{ml})$. The human granulosa-like tumor cell line, KGN, that was established by Nishi et al. (2001) was obtained from Riken Cell Bank (Tsukuba, Japan). KGN cells were cultured in DMEM/F-12 medium supplemented with $10 \%$ (v/v) FCS, penicillin $(100 \mathrm{U} / \mathrm{ml})$ and streptomycin $(100 \mu \mathrm{g} / \mathrm{ml})$. The SV-HFO human osteoblastic cells were a kind gift from Dr Hideki Chiba (Sapporo Medical University, Sapporo Japan). SV-HFO cells were maintained in DMEM supplemented with $10 \%(\mathrm{v} / \mathrm{v})$ FCS, penicillin $(100 \mathrm{U} / \mathrm{ml})$ and streptomycin $(100 \mu \mathrm{g} / \mathrm{ml})$. Cells were maintained as monolayer cultures in $10 \mathrm{~cm}$ dishes at $37^{\circ} \mathrm{C}$ in an atmosphere of $5 \%$ $\mathrm{CO}_{2}-95 \%$ air.

\section{Aromatase assay}

Aromatase activity in H295R cells was measured by the tritiated-water method based upon Ackerman et al. (1981). H295R cells were seeded at $2.5 \times 10^{4}$ cells/well on $24-$ well plates. After $24 \mathrm{~h}$ of culturing, the medium was replaced with the treatment medium (DMEM/F-12 with BSA $(0.01 \mathrm{mg} / \mathrm{ml}), 1 \%(\mathrm{v} / \mathrm{v})$ ITS plus, penicillin $(25$ $\mathrm{U} / \mathrm{ml})$ and streptomycin $(25 \mathrm{mg} / \mathrm{ml}))$. After a $24-\mathrm{h}$ incubation, the medium was replaced with the treatment medium containing the chemical compounds. After treatment for $24 \mathrm{~h}$, the medium was replaced with the assay medium (DMEM/F-12 with penicillin $(25 \mathrm{U} / \mathrm{ml})$ and streptomycin $(25 \mu \mathrm{g} / \mathrm{ml}))$ containing $30 \mathrm{pmol} \quad[1 \beta-$ ${ }^{3} \mathrm{H}$ androstenedione. After a $2-\mathrm{h}$ incubation at $37{ }^{\circ} \mathrm{C}$, $200 \mu \mathrm{l}$ of incubation media was mixed with $200 \mu \mathrm{l}$ of $30 \%$ trichloroacetic acid and the mixture was vortexed 
vigorously. After centrifugation, $200 \mu \mathrm{l}$ of the upper aqueous phase was mixed with $400 \mu \mathrm{l}$ DCC $(5 \%$ (w/v) charcoal, $0.5 \%(\mathrm{w} / \mathrm{v})$ dextran) and the mixture was vortexed vigorously. After centrifugation, $200 \mu \mathrm{l}$ of supernatant was mixed with $1 \mathrm{ml}$ ACS II aqueous counting scintillant. The count of ${ }^{3} \mathrm{HOH}$ that was released during the aromatization of $\left[1 \beta^{3} \mathrm{H}\right]$ androstenedione was measured. The amount of protein in the H295R cells in each well was measured with a BCA protein assay kit after protein extraction with $0 \cdot 1 \%$ SDS. The ${ }^{3} \mathrm{HOH}$ count was normalized using the amount of protein.

\section{$R T-P C R$}

$\mathrm{H} 295 \mathrm{R}$ cells were seeded at the population of $5 \times 10^{6} \mathrm{cells} /$ dish on $10-\mathrm{cm}$ dishes. After a $24-\mathrm{h}$ culture, the medium was replaced with the treatment medium. After incubation for $24 \mathrm{~h}$, the medium was replaced with the treatment medium containing the chemical compounds. After another 24-h incubation, total RNA was extracted using ISOGEN. First-strand cDNA was prepared from total RNA using Oligo dT primer $\left(\operatorname{pd}(\mathrm{T})_{12-18}\right)$, human placenta ribonuclease inhibitor and AMV reverse transcriptase according to the manufacturer's instructions. RT-PCR of the gene transcripts of CYP19 and glyceraldehyde-3-phosphate dehydrogenase (GAPDH) was performed on $1 \mu \mathrm{l}$ of first-strand cDNA using Taq polymerase and oligonucleotide primers. The primers and PCR conditions were based upon Agarwal et al. (1995), with some modifications. RT7 and RT8 primer were used to amplify the 196 base pairs consisting of partial sequences of exon II and exon III of the CYP19 gene. The cycles were: $94{ }^{\circ} \mathrm{C}$ for $5 \mathrm{~min} ; 10$ cycles of $94{ }^{\circ} \mathrm{C}$ for $30 \mathrm{~s}, 59^{\circ} \mathrm{C}$ for $30 \mathrm{~s}$ and $72{ }^{\circ} \mathrm{C}$ for $30 \mathrm{~s} ; 10$ cycles of $94{ }^{\circ} \mathrm{C}$ for $30 \mathrm{~s}, 57^{\circ} \mathrm{C}$ for $30 \mathrm{~s}$ and $72{ }^{\circ} \mathrm{C}$ for $30 \mathrm{~s} ; 12$ cycles of $94{ }^{\circ} \mathrm{C}$ for $30 \mathrm{~s}, 55^{\circ} \mathrm{C}$ for $30 \mathrm{~s}$ and $72{ }^{\circ} \mathrm{C}$ for $30 \mathrm{~s}$. RT3 and RT8 primer were used to amplify the 305 base pairs consisting of partial sequences of exon PII and exon III. The cycles were: $94^{\circ} \mathrm{C}$ for $5 \mathrm{~min} ; 10$ cycles of $94^{\circ} \mathrm{C}$ for $30 \mathrm{~s}, 60^{\circ} \mathrm{C}$ for $30 \mathrm{~s}$ and $72{ }^{\circ} \mathrm{C}$ for $30 \mathrm{~s} ; 10$ cycles of $94^{\circ} \mathrm{C}$ for $30 \mathrm{~s}, 55^{\circ} \mathrm{C}$ for $30 \mathrm{~s}$ and $72{ }^{\circ} \mathrm{C}$ for $30 \mathrm{~s} ; 15$ cycles of $94{ }^{\circ} \mathrm{C}$ for $30 \mathrm{~s}, 50{ }^{\circ} \mathrm{C}$ for $30 \mathrm{~s}$ and $72{ }^{\circ} \mathrm{C}$ for $30 \mathrm{~s}$. RT2 and RT8 primer were used for the amplification of 395 and 289 (truncated) base pairs consisting of partial sequences of exon I.3 and exon III. The cycles were: $94^{\circ} \mathrm{C}$ for $5 \mathrm{~min}$; 10 cycles of $94{ }^{\circ} \mathrm{C}$ for $30 \mathrm{~s}, 65^{\circ} \mathrm{C}$ for $30 \mathrm{~s}$ and $72{ }^{\circ} \mathrm{C}$ for $30 \mathrm{~s} ; 10$ cycles of $94{ }^{\circ} \mathrm{C}$ for $30 \mathrm{~s}, 60^{\circ} \mathrm{C}$ for $30 \mathrm{~s}$ and $72{ }^{\circ} \mathrm{C}$ for $30 \mathrm{~s} ; 17$ cycles of $94^{\circ} \mathrm{C}$ for $30 \mathrm{~s}, 55^{\circ} \mathrm{C}$ for $30 \mathrm{~s}$ and $72{ }^{\circ} \mathrm{C}$ for $30 \mathrm{~s}$. RT1 and RT8 primer were used for the amplification of 294 base pairs consisting of partial sequences of exon I.4 and exon III. The cycles were: $94{ }^{\circ} \mathrm{C}$ for $5 \mathrm{~min} ; 10$ cycles of $94^{\circ} \mathrm{C}$ for $30 \mathrm{~s}, 59^{\circ} \mathrm{C}$ for $30 \mathrm{~s}$ and $72{ }^{\circ} \mathrm{C}$ for $30 \mathrm{~s} ; 10$ cycles of $94{ }^{\circ} \mathrm{C}$ for $30 \mathrm{~s}, 57^{\circ} \mathrm{C}$ for $30 \mathrm{~s}$ and $72{ }^{\circ} \mathrm{C}$ for $30 \mathrm{~s} ; 15$ cycles of $94{ }^{\circ} \mathrm{C}$ for $30 \mathrm{~s}, 55^{\circ} \mathrm{C}$ for $30 \mathrm{~s}$ and $72{ }^{\circ} \mathrm{C}$ for $30 \mathrm{~s}$. GAPDH1 and GAPDH2 primer were used for the amplification of 306 base pairs consisting of partial sequences of human GAPDH mRNA. The cycles were: $94{ }^{\circ} \mathrm{C}$ for $5 \mathrm{~min} ; 25$ cycles of $94{ }^{\circ} \mathrm{C}$ for $30 \mathrm{~s}$, $63{ }^{\circ} \mathrm{C}$ for $30 \mathrm{~s}$ and $72{ }^{\circ} \mathrm{C}$ for $30 \mathrm{~s}$. The PCR products were visualized by ethidium bromide staining after electrophoresis on $1.5 \%$ agarose gel.

\section{Reporter vectors}

Several lengths of the genomic sequence of promoter I.3 and promoter II of human CYP19 gene were amplified by PCR using Pfu turbo DNA polymerase and one of the following: HAPII-AS1 primer $\left(5^{\prime}\right.$-TCCCCCGGGGCT CCTGTTGCTTCAGAGGG-3'), HAPI.3-S1 primer (5'-CGGGGTACCGTTCCTGAGTGGCACCTGAG C-3'), HAPII-S1 primer (5'-CGGGGTACCGACTCC ACCTCTGGAATGAGC-3'), HAPII-S2 primer (5'CGGGGTACCGGCTTTCAATTGGGAATGCACG TCAC-3'), HAPII-S3 primer (5'-CGGGGTACCACCC ACTCAAGGGCAAGATG-3') or HAPII-S4 primer (5'CGGGGTACCGCTGCAATTCAAGCCAAAAG-3'). PCR products were digested with KpnI and SmaI, and subcloned into KpnI-SmaI-digested pGL3-Basic. Mutations of the CLS and SF-1 motifs were generated according to Michael et al. (1997) using a Quikchange site-directed mutagenesis kit and oligonucleotide primers. CLSmut (+) primer (5'-GGCTTTCAATTGGGAATG GAATTCACTCTACCCACTCAAGGG-3') and CLSmut (-) primer (5'-CCCTTGAGTGGGTAGAGTGA ATTCCATTCCCAATTGAAAG CC-3') were used to prepare the reporter construct that had the mutation in the CLS motif. To prepare the SF-1-mutated reporter construct, SF-1 mut $(+)$ primer $\left(5^{\prime}\right.$-GGAACCTGAG ACTCTACCAAATTCAGAAATGCTGCAATTC-3') and SF-1 mut (-) primer (5'-GAATTGCAGCATTTCT GAATTTGGTAGAGTCTCAGGTTCC-3') were used. Mutation of the silencer element (S1) motif was generated according to Zhou and Chen (1998) using S1-TTCmut (+) primer (5'-CCAAGGTCAGAAATGCTGCAAAA GAAGCCAAAAGATCTTTC-3') and S1-TTCmut (-) primer (5'-GAAAGATCTTTTGGCTTCTTTTGCAG CATTTCTGACCTTGG-3').

\section{Transfection and luciferase assay}

H295R cells were seeded at $2.5 \times 10^{5}$ cells/well on $24-$ well plates. After a $24-\mathrm{h}$ culture, firefly luciferase reporter construct and seapansy luciferase internal control vector (phRL-KT) were transfected using Fugene 6 transfection reagent according to the manufacturer's instructions. After the 24-h transfection, the medium was replaced with treatment medium containing the chemical compounds and incubated for $8 \mathrm{~h}$. Luciferase activity was measured using a Dual-Luciferase reporter assay system and Sirius luminometer. 


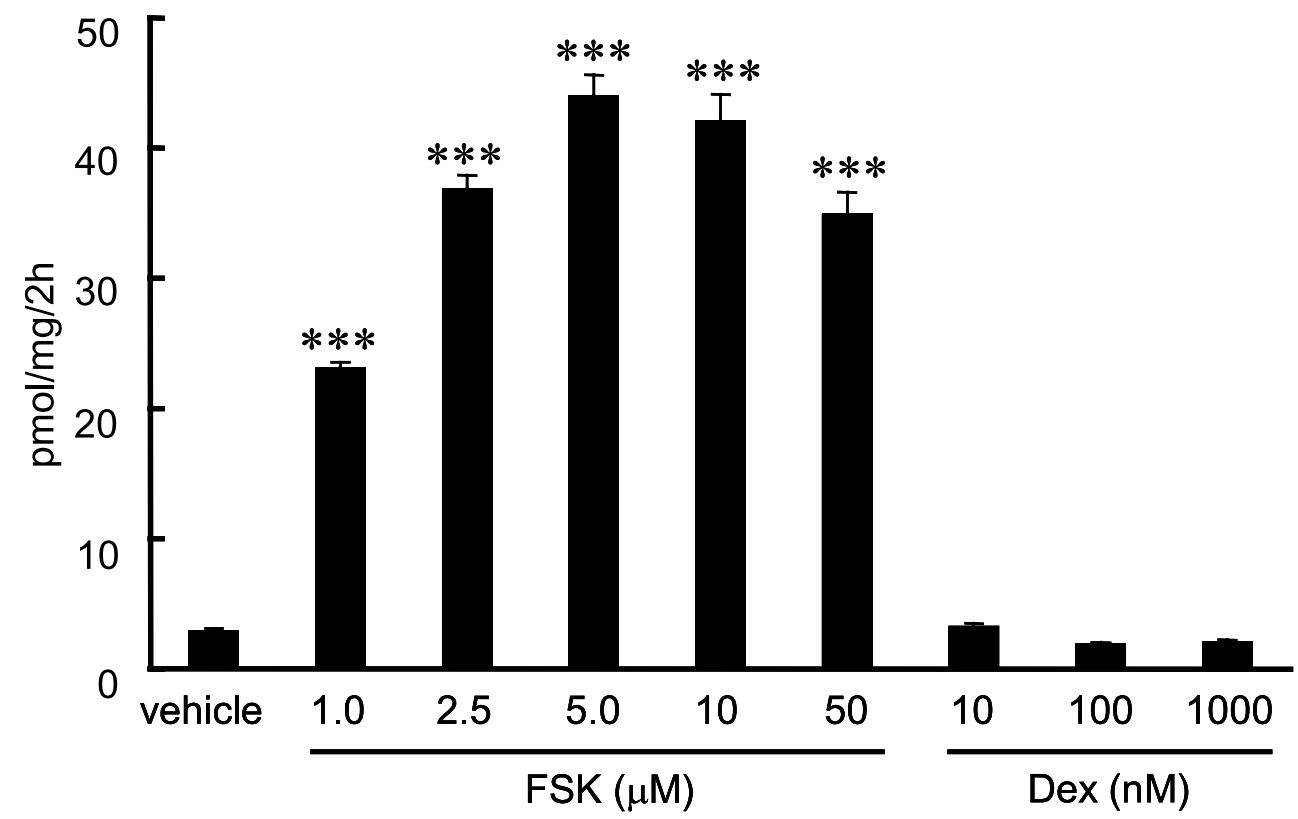

Figure 2 Aromatase activity in H295R. H295R cells were treated with $0 \cdot 1 \%$ ethanol (vehicle), or the indicated concentration of FSK or Dex for $24 \mathrm{~h}$. After incubation, aromatase activity was measured as described in the Materials and Methods section. Experiments were performed in triplicate. Error bars represent the S.E.M.; asterisks indicate the up-regulation compared with vehicle control; ${ }^{* * *} P<0 \cdot 001$.

\section{Statistical analysis}

The aromatase assay and transfection data for various treatments were compared with the data for vehicle treatments using Student's $t$-test.

\section{Results}

Aromatase activity in H295R

A tritiated-water assay method was used to verify the aromatase activity in H295R. We also checked whether two well-known aromatase stimulators (forskolin (FSK) and dexamethasone (Dex)) could stimulate aromatase activity in H295R. FSK is a well-known inducer of intracellular cAMP concentration through its activation of adenylate cyclase. In the ovary, the expression of aromatase activity and CYP19 gene transcript is primarily regulated by cAMP (Simpson et al. 1997). Dex is a synthetic glucocorticoid, and in human adipose tissue and osteoblasts, aromatase activity was stimulated by $100 \mathrm{nM}$ Dex (Zhao et al. 1995, Shozu \& Simpson 1998). Glucocorticoids are mainly secreted from the adrenal gland and H295R cells also synthesize cortisol; we therefore examined the possibility that glucocorticoids affected aromatase activity in an autocrine fashion. As shown in Fig. 2, aromatase activity in $\mathrm{H} 295 \mathrm{R}$ was detected by the tritiatedwater method (2.91 $\mathrm{pmol} / \mathrm{mg}$ per $2 \mathrm{~h})$. Aromatase activity was increased 15 -fold ( $44 \cdot 0 \mathrm{pmol} / \mathrm{mg}$ per $2 \mathrm{~h}$ ) by $5 \mu \mathrm{M}$ FSK. On the other hand, aromatase activity could not be stimulated by Dex. These results suggest that a signaling pathway involving cAMP, but not glucocorticoids, regulates the expression of aromatase activity in H295R.

\section{CYP19 gene transcript in H295R}

To determine if the up-regulation of aromatase in H295R was regulated at the stage of gene transcription, we performed RT-PCR on first-strand cDNAs from H295R after treatment with FSK or Dex. As shown in Fig. 3, RT-PCR, using the primers that correspond to exon II and exon III of the human CYP19 gene, detected the increase in CYP19 gene transcript after stimulation with FSK but not Dex. This result suggests that the expression of aromatase activity in H295R is regulated largely at the stage of gene transcription. RT-PCR using exon PII- and exon I.3-specific primers detected CYP19 gene transcripts that have the sequences of exon PII and exon I.3 in the cDNA from H295R. The intensities of the bands corresponding to exon PII and exon I.3 increased after stimulation with FSK, suggesting that the genomic promoter regions abutting exon PII and exon I.3 (promoter II and promoter I.3) are activated in H295R. Exon I.4 that is selected in human adipose tissue and osteoblasts was not selected in H295R. 


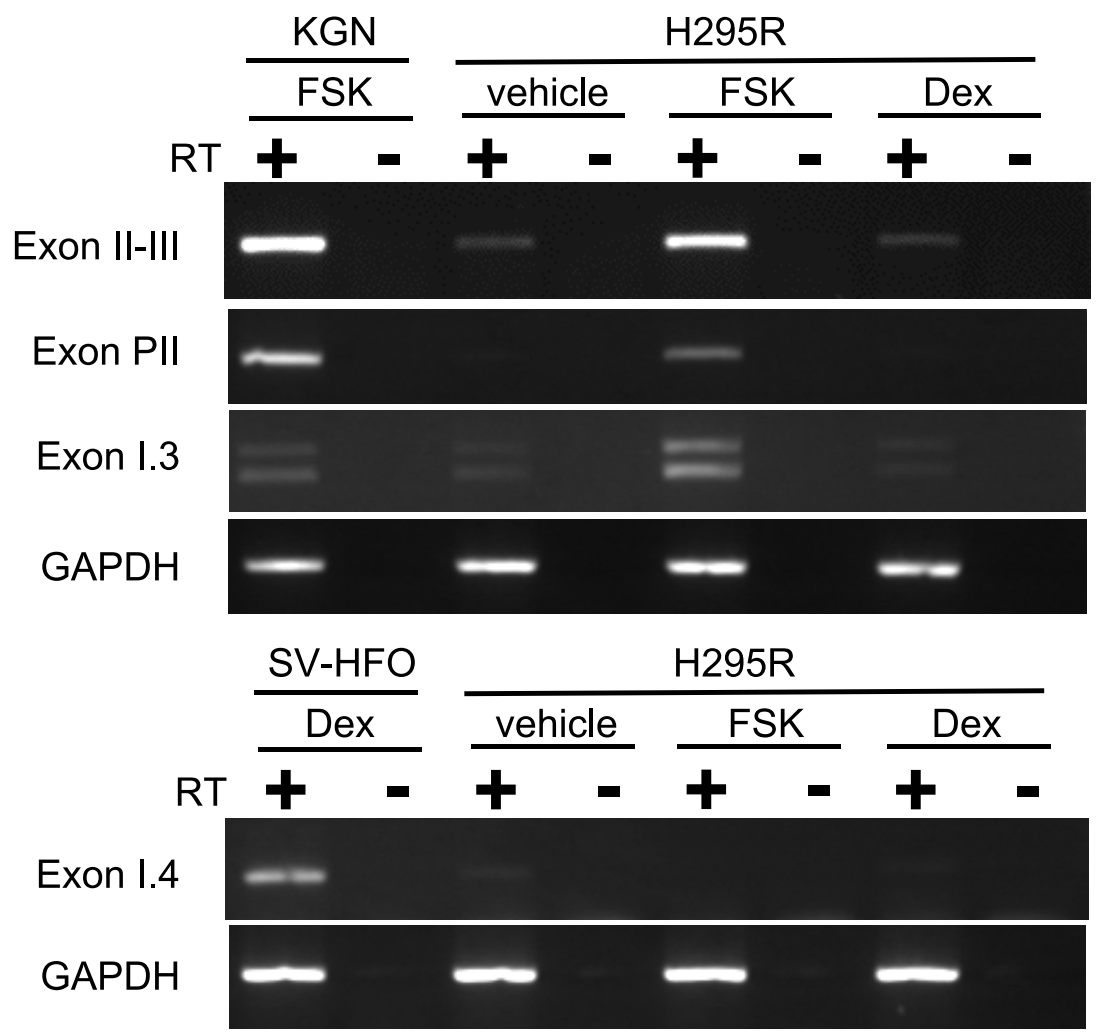

Figure 3 CYP19 gene transcript in H295R. H295R cells were incubated with $25 \mu$ M FSK or $100 \mathrm{nM}$ Dex for $24 \mathrm{~h}$. After incubation, total RNA was extracted and first-strand cDNA was prepared. RT-PCR using exon I-specific primers was performed. See Materials and Methods section for details. Total RNA from the human ovary-derived cell line KGN and the human osteoblastic cell line SV-HFO was used as the positive control.

\section{Promoter analysis}

From the RT-PCR results, we verified that promoter I.3 and promoter II were activated in H295R by transfection of the firefly luciferase reporter vector into H295R cells.
Promoter I.3 and promoter II are located within 717 base pairs upstream of exon PII/exon II (Fig. 4). Promoter II exists within exon I.3. As shown in Fig. 5, $-278 /+23$ Luc that harbors the entire sequence of promoter II was activated in a dose-dependent manner by FSK in H295R.

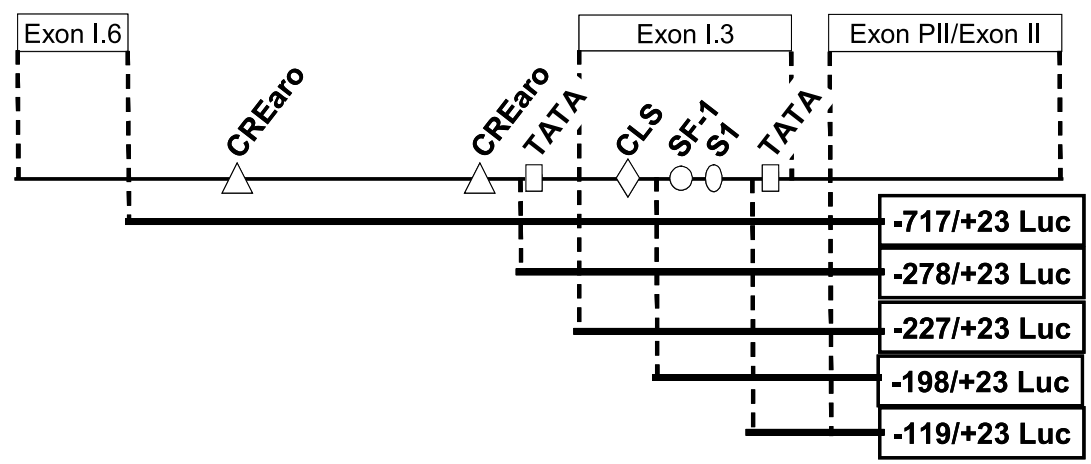

Figure 4 Position of exon I and putative transcription factor binding sites around exon II of the human CYP19 gene. The positions of exon I (top) and transcription factor binding sites (middle: CREaro, TATA, CLS, SF-1, S1) in the partial human genomic sequence of the CYP19 gene are indicated. The position of genomic sequences inserted into firefly luciferase reporter vector (bottom) is also indicated. 


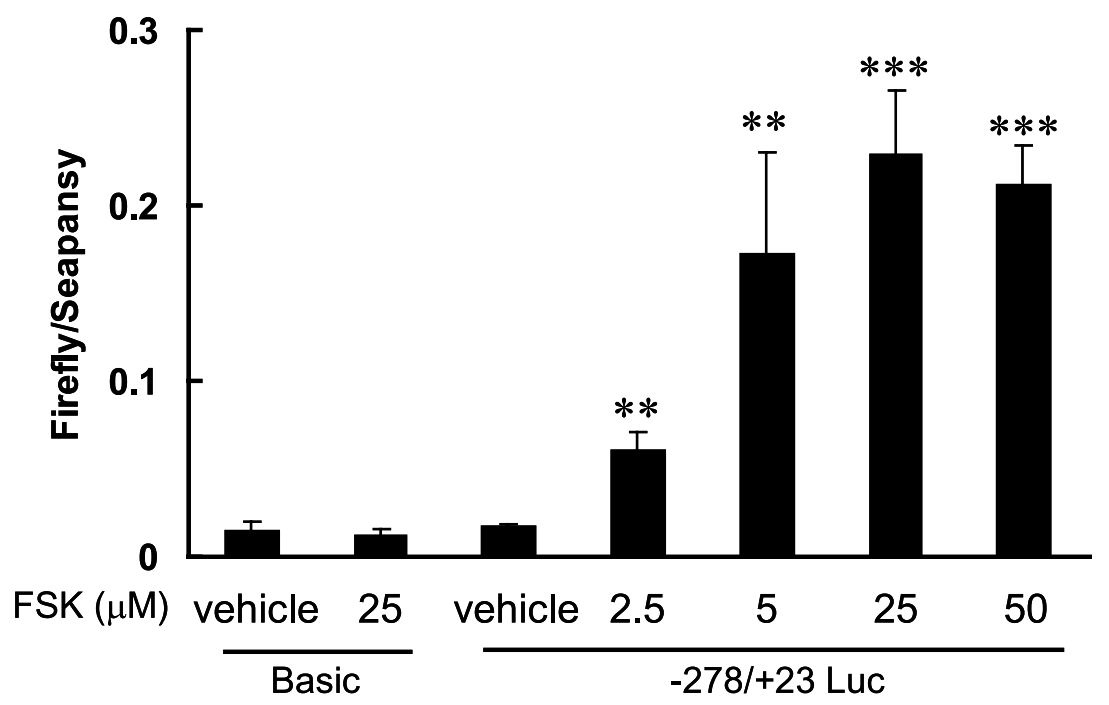

Figure 5 Activation of promoter II sequence of human CYP19 gene in H295R. - 278/+23 Luc firefly luciferase vector was transfected into H295R cells with a seapansy luciferase internal control vector (phRL-TK) using Fugene 6 transfection reagent. After $24 \mathrm{~h}$ of transfection, the cells were treated with $25 \mu \mathrm{M}$ FSK for $8 \mathrm{~h}$. Luciferase activity in the cell lysates was measured. Experiments were performed in triplicate. Error bars represent the S.E.M.; asterisks indicate up-regulation compared with the vehicle control; ${ }^{* *} P<0 \cdot 01$, $* * * P<0 \cdot 001$

Because the profile of the forskolin dose-dependency is similar to that of aromatase activity, we concluded that aromatase expression in $\mathrm{H} 295 \mathrm{R}$ is regulated at the stage of gene transcription.

The human CYP19 gene has several sequences that respond to the increase in intracellular cAMP concentration in the promoter I.3/II region. Although a consensus CRE does not exist, CREaro (Zhou \& Chen 1999) and the CLS (Michael et al. 1997) motifs have some homology to consensus CRE and have important roles in the responses of promoter I.3 and promoter II to cAMP. To verify the importance of these cAMP responsive sequences, we transfected the 5 -deleted series of the promoter I.3/II sequence and stimulated with $25 \mu \mathrm{M}$ FSK. As shown in Fig. 6, $-717 /+23$ Luc that has the full sequence of promoter I.3/II activity increased about sixfold in response to FSK. $-278 /+23$ Luc has half the activity compared with $-717 /+23$ Luc. The deleted $5^{\prime}$ sequence has two CREaro motifs and therefore this result reflects the importance of these motifs. $-227 /+23$ Luc, which has the full sequence of the promoter II sequence, was also activated by FSK. The cAMP sensitivity of $-717 /+23 \mathrm{Luc}$ and $-227 /+23 \mathrm{Luc}$ is in good agreement with the result of the RT-PCR experiment that suggested that promoter I. 3 and promoter II are activated in H295R cells. Another 29 base deletions $(-198 /+23$ Luc) caused almost complete abolishment of FSK sensitivity. This 29-base sequence has CLS, suggesting that this motif is critical for the cAMP response of the promoter region. The reporter activity of $-119 / 23$ Luc also has no
FSK sensitivity. These two constructs have almost the same activity profile as the empty firefly luciferase vector pGL3-Basic (Basic). There is another important sequence for the expression of steroidogenic P450 enzymes (steroidogenic factor-1 motif; SF-1) between -198 and - 119. However, CLS appears to be the most important motif for the expression of CYP19 in H295R.

The results of $5^{\prime}$ deletion analysis suggest that the CLS motif may be critical for the response of promoter II to FSK. Furthermore, the SF-1 motif is an important sequence for the regulation of steroidogenic P450 enzyme gene expression. In addition, the silencer element (S1) abuts the SF-1 motif. An S1 mutation increases promoter II activity in human adipose tissue (Zhou \& Chen 1998). Based on this information, we prepared mutated promoter II reporter vectors that have mutations in the CLS, SF-1 or S1 motifs. As shown in Fig. 7, a mutation in CLS completely abolished the response to FSK. Mutation of the SF-1 motif also abolished the response to FSK. These results seem to support the importance of these two motifs. The S1-mutated promoter II sequence has some FSK sensitivity, but diminished promoter activity, suggesting that the role of this motif in H295R would be different to its role in human adipose tissue.

\section{Discussion}

In the present study, we characterized aromatase activity, gene transcripts and promoter activity in the human 


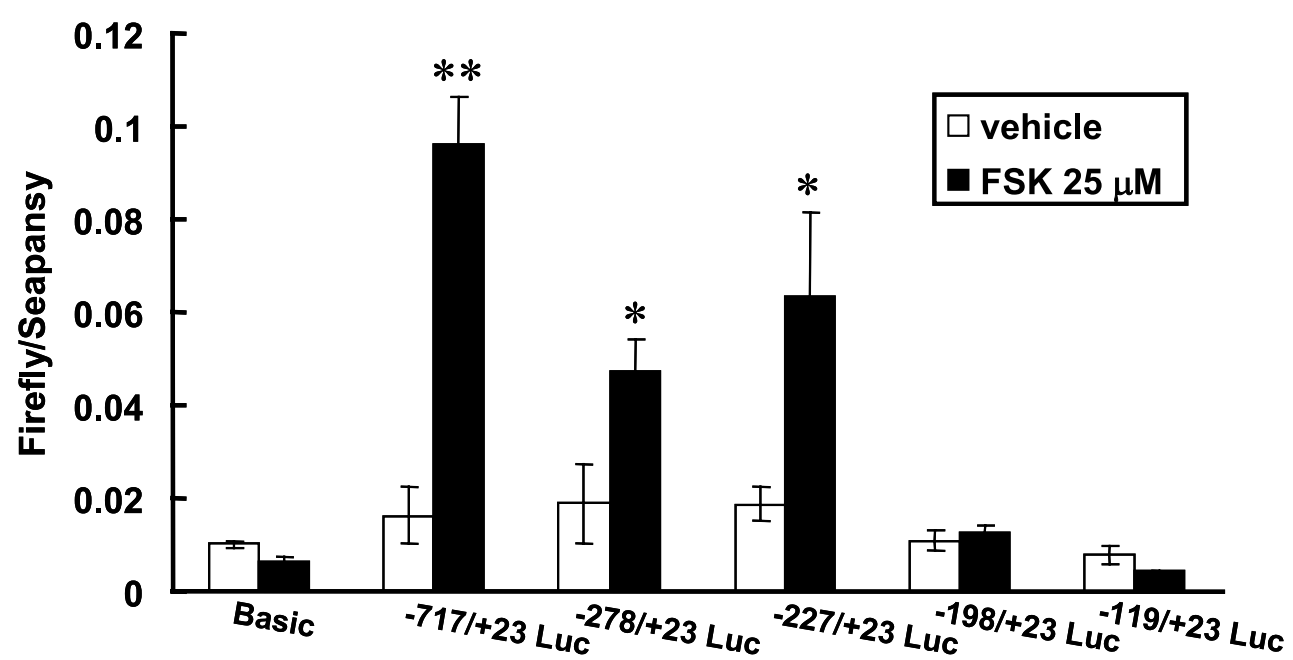

Figure 6 Deletion analysis of promoter I.3/II region in the CYP19 gene. Firefly luciferase reporter vectors harboring $5^{\prime}$-deleted series of promoter I.3/II region in human CYP19 gene were transfected into H295R cells with a seapansy luciferase internal control vector (phRL-TK) using Fugene 6 transfection reagent. After $24 \mathrm{~h}$ of transfection, the cells were treated with $25 \mu \mathrm{M}$ FSK for $8 \mathrm{~h}$. Luciferase activity in the cell lysates was measured. Experiments were performed in triplicate. Error bars represent the S.E.M.; asterisks indicate up-regulation compared with the vehicle control; ${ }^{\star} P<0 \cdot 05,{ }^{*} P<0 \cdot 01$.

adrenocortical carcinoma cell line H295R. Aromatase activity and gene transcripts were up-regulated by an intracellular signaling pathway involving cAMP, but not by glucocorticoids; this suggests that ACTH or other agents that increase intracellular cAMP concentration are stimulators of aromatase activity in estrogen-secreting adrenal tumors in vivo. Further experiments are needed to identify the true stimulator in vivo. Exon I.3 and exon PII were selected as the $5^{\prime}$ untranslated regions. These finding are in good agreement with results from adrenal tumors (Young et al. 1996, Watanabe et al. 2000). Dependency on cAMP and exon I usage indicate that the molecular mechanism of aromatase expression in adrenal tumors is similar to that in the ovary. Promoter I.3 and promoter II are also activated in human adipose tissue, however, the mutation of the $\mathrm{S} 1$ motif did not increase promoter activity but rather decreased it in H295R cells. Therefore, the mechanism of activation of promoter I.3/II in H295R

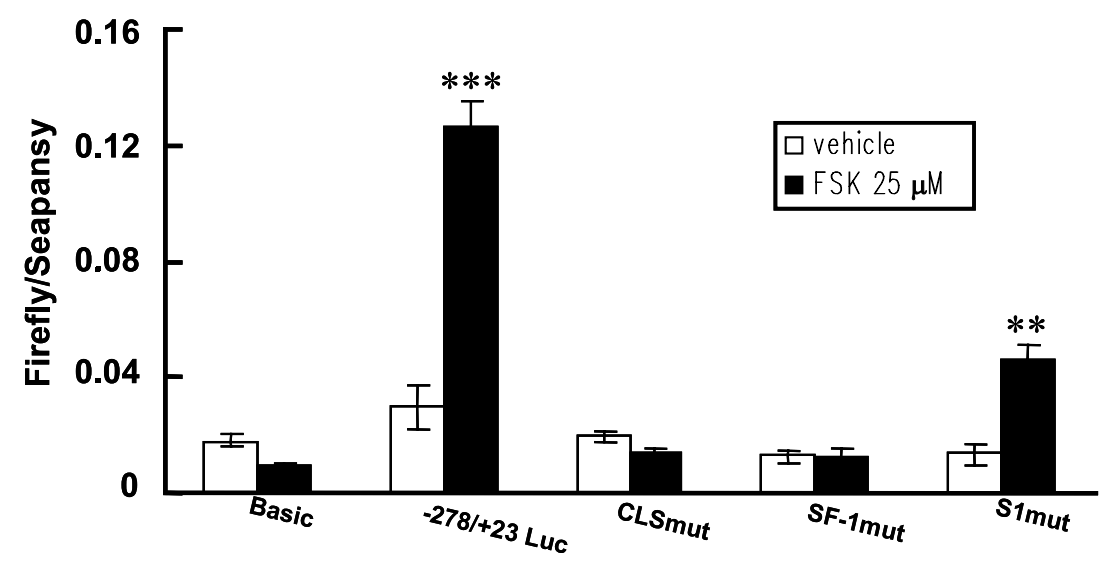

Figure 7 Mutation analysis of promoter II region in the CYP19 gene. $-278 /+23$ Luc and its mutants that have mutations in CLS, SF-1 and S1 motifs were transfected into H295R with a seapansy luciferase internal control vector (phRL-TK) using Fugene 6 transfection reagent. After $24 \mathrm{~h}$ of transfection, the cells were treated with $25 \mu \mathrm{M}$ FSK for $8 \mathrm{~h}$. Luciferase activity in the cell lysates was measured. Experiments were performed in triplicate. Error bars represent the S.E.M.; asterisks indicate up-regulation compared with the vehicle control; ${ }^{* *} P<0 \cdot 01,{ }^{* * *} P<0 \cdot 001$. 
would appear to be different to that in adipose tissue. The molecular mechanism of CYP19 gene expression may even be different to that in ovary. For example, CREbinding protein (CREB), which is reported to be a binding protein for the CLS motif in promoter II (Michael et al. 1997), is not expressed in H295R cells; elevated expression of CRE modulator (CREM) may compensate for the lack of CREB (Groussin et al. 2000). Further characterization of the molecular mechanism, including the binding protein for CLS and S1 motifs, may clarify the specific mechanism of CYP19 gene expression in adrenal tumors.

The H295R cell line was established as NCI-H295 from a 48-year-old woman (Gazdar et al. 1990) whose menses had ceased. This patient had no symptoms caused by high concentrations of estrogen. In addition, radioimmunoassay (RIA) analysis of the culture media of this cell line failed to detect either estrone or estradiol. This could be because of the very low concentrations of aromatase substrates. RIA also failed to detect testosterone and the concentration of androstenedione was very low (dehydroepiandrosterone was $75900 \mathrm{ng} / 10^{8}$ cells per $24 \mathrm{~h}$, but androstenedione was $28 \mathrm{ng} / 10^{8}$ cells per $24 \mathrm{~h}$ ). Taking into consideration the high expression of aromatase activity in H295R cells, the loss of estrogen excess in the donor patient was caused by the low concentration of aromatase substrates, at least around the tumor. Boys would have adequate concentrations of androstenedione and testosterone, most likely from the testes. In girls, theca cells in the ovaries would secrete sufficient levels of aromatizable androgens. Further investigation is needed of the systemic or local conditions that cause estrogen excess, including aromatase substrate and up-regulators of aromatase expression in adrenal tumors. H295R cells may be a powerful tool with which to clarify the mechanism underlying this phenomenon.

Some adrenal tumors have high aromatase activity whereas normal adrenal tissues have no detectable aromatase activity. Thus, some specific molecular mechanism that makes adrenal cells transform into a tumor may be involved in expression of the CYP19 gene in adrenal tumors. Comparison of the molecular mechanism of promoter I.3/II activation between normal adrenal cells and H295R should provide some useful information about the molecular mechanism of transformation into an adrenal tumor.

Aromatase inhibitors may be potent tools with which to treat precocious puberty in patients with estrogensecreting adrenal tumors. Unfortunately, the inhibition of aromatase activity throughout the entire body inhibits aromatase activity in peripheral tissues, including bone. Inhibition of aromatase activity in bone tissue would affect bone growth and the maintenance of bone mineral density. To avoid this unwanted effect, adrenal-specific inhibition of aromatase expression is required. The development of an adrenal-specific inhibitor would be based upon an adrenal-specific molecular mechanism of CYP19 expression. H295R cells would appear to be a useful tool for the development of this type of inhibitor.

In summary, H295R cells that have similar profiles of aromatase expression would be a powerful tool with which to investigate the effects of hormones and chemicals, as well as their molecular mechanisms, upon aromatase in adrenal tumors.

\section{Acknowledgements}

We thank Prof. J I Mason and Dr Hideki Chiba for the H295R and SV-HFO cells respectively, and $\mathrm{Mr}$ Fumihiko Yukinawa for his technical assistance.

\section{References}

Ackerman GE, Smith ME, Mendelson CR, MacDonald PC \& Simpson ER 1981 Aromatization of androstenedione by human adipose tissue stromal cells in monolayer culture. Journal of Clinical Endocrinology and Metabolism 53 412-417.

Agarwal VR, Bulun SE \& Simpson ER 1995 Quantitative detection of alternatively spliced transcripts of the aromatase cytochrome P450 (CYP19) gene in aromatase-expressing human cells by competitive RT-PCR. Molecular and Cellular Probes 9 453-464.

Gazdar AF, Oie HK, Shackleton CH, Chen TR, Triche TJ, Myers CE, Chrousos GP, Brennan MF, Stein CA \& Rocca VL 1990 Establishment and characterization of a human adrenocortical carcinoma cell line that expresses multiple pathways of steroid biosynthesis. Cancer Research 50 5488-5496.

Gell JS, Oh J, Rainey WE \& Carr BR 1998 Effect of estradiol on DHEAS production in the human adrenocortical cell line, H295R. Journal of the Society for Gynecologic Investigation 5 144-148.

Groussin L, Massias JF, Bertagna X \& Bertherat J 2000 Loss of expression of the ubiquitous transcription factor cAMP response element-binding protein (CREB) and compensatory overexpression of the activator CREMtau in the human adrenocortical cancer cell line H295R. Journal of Clinical Endocrinology and Metabolism $\mathbf{8 5}$ 345-354.

Honda S, Harada N \& Takagi Y 1996 The alternative exons 1 of the mouse aromatase cytochrome P-450 gene. Biochimica et Biophysica Acta 1305 145-150.

Michael MD, Michael LF \& Simpson ER 1997 A CRE-like sequence that binds CREB and contributes to CAMP-dependent regulation of the proximal promoter of the human aromatase P450 (CYP19) gene. Molecular and Cellular Endocrinology 134 147-156.

Nishi Y, Yanase T, Mu Y, Oba K, Ichino I, Saito M, Nomura M, Mukasa C, Okabe T, Goto K et al. 2001 Establishment and characterization of a steroidogenic human granulosa-like tumor cell line, KGN, that expresses functional follicle-stimulating hormone receptor. Endocrinology 142 437-445.

Ohno S, Shinoda S, Toyoshima S, Nakazawa H, Makino T \& Nakajin S 2002 Effects of flavonoid phytochemicals on cortisol production and on activities of steroidogenic enzymes in human adrenocortical H295R cells. Journal of Steroid Biochemistry and Molecular Biology 80 355-363.

Phornphutkul C, Okubo T, Wu K, Harel Z, Tracy TF Jr, Pinar H, Chen S, Gruppuso PA \& Goodwin G 2001 Aromatase P450 expression in a feminizing adrenal adenoma presenting as isosexual precocious puberty. Journal of Clinical Endocrinology and Metabolism 86 649-652.

Sanderson JT, Seinen W, Giesy JP \& van den Berg M 2000 2-Chloro-s-triazine herbicides induce aromatase (CYP19) activity 
in H295R human adrenocortical carcinoma cells: a novel mechanism for estrogenicity? Toxicological Sciences 54 121-127.

Sanderson JT, Letcher RJ, Heneweer M, Giesy JP \& van den Berg M $2001 a$ Effects of chloro-s-triazine herbicides and metabolites on aromatase activity in various human cell lines and on vitellogenin production in male carp hepatocytes. Environmental Health Perspectives 109 1027-1031.

Sanderson JT, Slobbe L, Lansbergen GW, Safe S \& van den Berg M $2001 \mathrm{~b}$ 2,3,7,8-Tetrachlorodibenzo-p-dioxin and diindolylmethanes differentially induce cytochrome P450 1A1, 1B1, and 19 in H295R human adrenocortical carcinoma cells. Toxicological Sciences $\mathbf{6 1}$ $40-48$.

Sanderson JT, Boerma J, Lansbergen GW \& van den Berg M 2002 Induction and inhibition of aromatase (CYP19) activity by various classes of pesticides in H295R human adrenocortical carcinoma cells. Toxicology and Applied Pharmacology 182 44-54.

Sasano H \& Harada N 1998 Intratumoral aromatase in human breast, endometrial, and ovarian malignancies. Endocrine Reviews 19 593-607.

Sasano H, Takahasi K, Satoh F, Nagura H \& Harada N 1998 Aromatase in the human central nervous system. Clinical Endocrinology 48 325-329.

Sebastian S \& Bulun SE 2001 A highly complex organization of the regulatory region of the human CYP19 (aromatase) gene revealed by the Human Genome Project. Journal of Clinical Endocrinology and Metabolism 86 4600-4602.

Shozu M \& Simpson ER 1998 Aromatase expression of human osteoblast-like cells. Molecular and Cellular Endocrinology 139 $117-129$
Simpson ER, Zhao Y, Agarwal VR, Michael MD, Bulun SE, Hinshelwood MM, Graham-Lorence S, Sun T, Fisher CR, Qin K \& Mendelson CR 1997 Aromatase expression in health and disease. Recent Progress in Hormone Research 52 185-213.

Watanabe T, Yasuda T, Noda H, Wada K, Kazukawa I, Someya T, Minamitani K, Minagawa M, Wataki K, Matsunaga T et al. 2000 Estrogen secreting adrenal adenocarcinoma in an 18-month-old boy: aromatase activity, protein expression, mRNA and utilization of gonadal type promoter. Endocrine Journal 47 723-730.

Young J, Bulun SE, Agarwal V, Couzinet B, Mendelson CR, Simpson ER \& Schaison G 1996 Aromatase expression in a feminizing adrenocortical tumor. Journal of Clinical Endocrinology and Metabolism 81 3173-3176.

Zhao Y, Mendelson CR \& Simpson ER 1995 Characterization of the sequences of the human CYP19 (aromatase) gene that mediate regulation by glucocorticoids in adipose stromal cells and fetal hepatocytes. Molecular Endocrinology 9 340-349.

Zhou D \& Chen S 1998 Characterization of a silencer element in the human aromatase gene. Archives of Biochemistry and Biophysics 353 213-220.

Zhou D \& Chen S 1999 Identification and characterization of a cAMP-responsive element in the region upstream from promoter 1.3 of the human aromatase gene. Archives of Biochemistry and Biophysics 371 179-190.

Received 3 June 2003

Accepted 26 September 2003 